\title{
High Temperature Characterization of Binary and Ternary Bi Alloys Microalloyed with $\mathrm{Cu}$ and $\mathrm{Ag}$
}

\author{
Meiqi $\mathrm{Yu}^{1}$, Kazuhiro Matsugi ${ }^{1}$, Zhefeng $\mathrm{Xu}^{1, *}$, Yongbum $\mathrm{Choi}^{1}{ }^{1}$, Jinku $\mathrm{Yu}^{2}$, Satoshi Motozuka ${ }^{3}$, \\ Yoshiyuki Nishimura $^{4}$ and Ken-ichiro Suetsugu ${ }^{5}$
}

${ }^{1}$ Department of Mechanical Materials Engineering, Hiroshima University, Higashi-Hiroshima 739-8527, Japan

${ }^{2}$ State Key Laboratory of Metastable Materials Science and Technology, Yanshan University, Hebe Street West 438\#, Qinhuangdao 066004, China

${ }^{3}$ Department of Mechanical Engineering, National Institute of Technology, Gifu College, Motosu 501-0495, Japan

${ }^{4}$ Engineering Department, OM Sangyo Co. Ltd., Okayama 700-0971, Japan

${ }^{5}$ Center for Environmental Management, Kobe University, Kobe 657-8501, Japan

The s-orbital energy level $(M k)$ of alloying elements in a Bi cluster was used to determine the composition for alloys of this system for use as $\mathrm{Pb}$-free high-temperature solders. Binary $\mathrm{Bi}-\mathrm{Cu}$ and $\mathrm{Bi}-\mathrm{Ag}$ alloys with $\triangle M k$ of $0.013-0.343$ and ternary Bi-2.0Ag- $0.5 \mathrm{Cu}$ and Bi$5.0 \mathrm{Ag}-0.5 \mathrm{Cu}$ alloys with $\Delta M k$ of 0.180 and 0.379 , respectively, were fabricated and tensile tested at $423 \mathrm{~K}$; here, $\Delta M k$ is the compositional average of $M k$. The flow stress and fracture strain at $423 \mathrm{~K}$ increased after the alloying elements were added to the alloys. The relationships between the $0.2 \%$ proof stress, ultimate tensile strength or fracture strain, and $\Delta M k$ were similar to those determined previously through tests performed at $293 \mathrm{~K}$. Thus, these relationships could be useful for predicting the stress and fractures strain levels based on $\Delta M k$, regardless of the temperature and alloy composition. Moreover, a transition from ductility to brittleness was observed at 348-373 K for both ternary alloys. In addition, the melting points of the ternary alloys lay between 536 and $538 \mathrm{~K}$, indicating that the alloys would be suitable as hightemperature solders. The contact angles of molten droplets of 10 of the experimental binary and ternary alloys on a $\mathrm{Cu}$ plate as determined at $973 \mathrm{~K}$ were $24-30^{\circ}$. This confirmed that the alloys exhibited good wettability with respect to $\mathrm{Cu}$. Finally, the ternary $\mathrm{Bi}-2.0 \mathrm{Ag}-0.5 \mathrm{Cu}$ and $\mathrm{Bi}-$ $5.0 \mathrm{Ag}-0.5 \mathrm{Cu}$ alloys showed thermal conductivities of 12.1 and $15.9 \mathrm{~W} / \mathrm{m} / \mathrm{K}$, respectively, at $373 \mathrm{~K}$; these were lower than that $(30.4 \mathrm{~W} / \mathrm{m} / \mathrm{K})$ of Pb-5Sn. [doi:10.2320/matertrans.MAW201710]

(Received July 27, 2017; Accepted November 14, 2017; Published January 25, 2018)

Keywords: lead-free solders, high-temperature solders, bismuth alloys, alloy design

\section{Introduction}

Solder alloys with high-melting points are used widely in power semiconductor packaging. High-lead-content alloys, which have been employed as high-temperature solder alloys, have a solidus temperature of more than $533 \mathrm{~K}^{1)}$. In recent years, owing to the RoHS (The Restriction of the Use of Certain Hazardous Substances in Electrical and Electronic Equipment Regulations 2012) and End of Life Vehicles Directives of EU, lead-free high-temperature solder alloys have been promoted in the electronics industry ${ }^{2)}$. Therefore, significant efforts are being devoted all over the world towards the development of lead-free solders. However, there have not been significant advances in the development of lead-free solders for high-temperature applications $^{3,4)}$. Several research groups have focused on Au-Sn, $\mathrm{Zn}-\mathrm{Sn}$, and Bi-Ag system alloys as potential lead-free alloys, based on their thermal and electricity properties and their melting points ${ }^{5-12)}$. However, Au system alloys find limited use as high-temperature solders because of the high cost of $\mathrm{Au}^{5)}$. The applicability of $\mathrm{Zn}$ system alloys is also limited because of the oxidability of $\mathrm{Zn}^{6-9)}$. On the other hand, the melting point of $\mathrm{Bi}$ is $544 \mathrm{~K}$, which is similar to that of conventional high-temperature $\mathrm{Pb}-\mathrm{Sn}$ solders ${ }^{10-12)}$. Moreover, $\mathrm{Bi}$ is not only cheap but is also not harmful to human health and the environment. Thus, Bi system alloys are being considered for use as $\mathrm{Pb}$-free alloys for high-temperature solders $^{13,14)}$.

So far, high-performance alloys have been developed

*Corresponding author, E-mail: zfxu@ hiroshima-u.ac.jp through trial-and-error experiments performed based on a few empirical rules. In order to develop new alloys more efficiently, a theoretical design approach is strongly needed. The concept of d-electrons based on the theoretically determined electronic structures of alloys using discrete variational (DV)-X $\alpha^{15-17)}$ cluster calculations was proposed by Morinaga et al. ${ }^{18,19)}$ This concept was first used in the case of austenitic Ni, C, and Fe alloys, wherein the phase boundary as well as a few physical and mechanical properties were predicted based on electronic parameters such as the d-orbital energy level and bond order. Moreover, the compositional optimization of $\mathrm{Al}^{20}$ system alloys as a simple metal was performed based on the s-orbital energy level $(M k)^{15-17)}$. The relationship between the dislocation density (or hindrance to dislocation migration) and $\Delta M k$ has also been investigated previously ${ }^{21)}$. It was concluded that the $\triangle M k$ value could be used as an indicator of the level of solid-solution hardening in ternary $\mathrm{Al}-1.5 \mathrm{Mn}-\mathrm{xMg}$ alloys consisting of a mono phase.

We were able to determine the $M k$ value of a few alloying elements in a Bi cluster model by using the DV-X $\alpha$ cluster method $^{22)}$. It was observed that there exists a relationship between the ultimate tensile strength or fracture strain at $293 \mathrm{~K}$ and $\Delta M k$ in the case of binary Bi-Cu/-Ag/- $\mathrm{Zn}$ alloys with near-eutectic compositions and that this relationship was in keeping with the results of tensile tests performed at $293 \mathrm{~K}$ for ternary Bi-Ag-Cu alloys ${ }^{22}$. These ternary alloys exhibited the desired properties, namely, a ultimate tensile strength of $20 \mathrm{MPa}$ and fracture strain of $5 \%$ at $293 \mathrm{~K}^{23}$. The mechanical properties of the alloys such as their tensile properties and hardness could be predicted based on the 
$\triangle M k$ value. However, the high-temperature properties of the Bi system alloys were not investigated.

In this study, the high-temperature tensile properties were measured on binary and ternary $\mathrm{Bi}-\mathrm{Cu}-\mathrm{Ag}$ system alloys proposed by $\triangle M k$ parameter. In contrast, the melting points, thermal conductivities, and wettabilities with respect to $\mathrm{Cu}$ of the alloys at high temperatures were also measured, in order to evaluate their suitability for practical applications. The desired characteristics of the high-temperature solders were considered to be a melting point higher than $533 \mathrm{~K}^{1)}$, and a contact angle on $\mathrm{Cu}$ of less than $90^{\circ}$.

\section{Experiment Procedure}

\subsection{Materials and fabrication process}

Stick-like Bi (purity of 99.99\%), granular Ag (purity of $99.99 \%$ ), and laminar $\mathrm{Cu}$ (purity of $99.9 \%$ ) were placed in a graphite crucible, which was then set in an electric furnace in air. The diameters of the $\mathrm{Bi}$ and $\mathrm{Ag}$ samples were 2-3 mm, while the thickness of the $\mathrm{Cu}$ sample was $1 \mathrm{~mm}$. Once all the starting materials had melted, the melt was mixed with a ceramic stick at $773 \mathrm{~K}$ and held at this temperature for $1.8 \mathrm{ks}$. Next, the melt was poured into a casting mold heated to $773 \mathrm{~K}$. The resulting ingot which had a diameter of $15 \mathrm{~mm}$ and height of $115 \mathrm{~mm}$, was air cooled to $293 \mathrm{~K}$. The compositions of the experimental alloys are listed in Table 1.

\subsection{Characterization of alloys at high temperatures}

The microstructures of the alloys were observed using scanning electron microscopy (SEM). Tensile tests were performed on the alloys at 323, 348, 373, 423, and $473 \mathrm{~K}$ in air using a mechanical testing machine (Autograph DCS-R-5000, Shimadzu Corporation, Japan); the tests were performed using an initial strain rate of $3.4 \times 10^{-4} \mathrm{~s}^{-1}$. The dimensions of the gauge section of the tensile test specimens were $6 \mathrm{~mm}$ (diameter) $\times 20 \mathrm{~mm}$ (length). In addition, the fracture surfaces of the tensile samples were observed by SEM. Differential scanning calorimetry (DSC) was used to characterize the melting points of the alloys. Rectangular samples with dimensions of $3 \times 3 \times 3 \mathrm{~mm}^{3}$ were employed for the purpose. The DSC measurements were performed in an Ar atmosphere. A heating rate of $5 \mathrm{~K} / \mathrm{min}$ was used, and the temperature was varied from 293 to $673 \mathrm{~K}$, with the samples being held for $300 \mathrm{~s}$ at $673 \mathrm{~K}$. As shown in Fig. 1,

Table 1 Compositions of binary and ternary Bi system alloys and their $\triangle M k$ values.

\begin{tabular}{cc}
\hline Alloy (mass\%) & $\Delta M k$ \\
\hline Bi- $0.15 \mathrm{Cu}$ & 0.013 \\
\hline Bi- $0.25 \mathrm{Cu}$ & 0.021 \\
\hline Bi-0.5Cu & 0.042 \\
\hline Bi- $0.75 \mathrm{Cu}$ & 0.062 \\
\hline Bi-1.0Cu & 0.082 \\
\hline Bi-2.5Ag & 0.176 \\
\hline Bi-5.0Ag & 0.343 \\
\hline Bi-2.0Ag-0.5Cu & 0.180 \\
\hline Bi-5.0Ag-0.5Cu & 0.379
\end{tabular}

the contact angles between molten droplets of the experimental alloys and a $\mathrm{Cu}$ plate (purity of $99.9 \%$ ) were measured in the atmosphere-controlled chamber with Mo heaters. Figure 2 shows profiles of press and temperature of $\mathrm{Cu}$ plate. First, the vacuum furnace was evacuated to $1.5 \times$ $10^{-3} \mathrm{~Pa}$ and then heated to $973 \mathrm{~K}$ while using $\mathrm{Ar}$ as the shielding gas at a flow rate of $1.67 \times 10^{-5} \mathrm{~m}^{3} / \mathrm{s}$ up to a pressure of $1.0 \times 10^{5} \mathrm{~Pa}$. Then, a droplet of the molten alloy being tested was placed on the $\mathrm{Cu}$ plate at $973 \mathrm{~K}$ and photographed after $120 \mathrm{~s}$. The volume of the droplets of the alloys was approximately $111 \mathrm{~mm}^{3}$. The surface of the $\mathrm{Cu}$ plate was finished to the polishing by $\mathrm{Al}_{2} \mathrm{O}_{3}$ particles paste with $0.3 \mu \mathrm{m}$. Further, the thermal conductivities of the alloys were measured using a laser flash thermal constant measurement system (TC-700, ULVAC-RIKO Inc., Japan) ${ }^{9)}$ at 293, 323 , and $373 \mathrm{~K}$. The test samples, which had dimensions of 10 (diameter) $\times 1 \mathrm{~mm}^{3}$ were also finished to the polishing by $\mathrm{Al}_{2} \mathrm{O}_{3}$ particles paste with $0.3 \mu \mathrm{m}$.

\subsection{Electronic parameter representing alloying effects}

An s-orbital energy level exists above the Fermi energy level of an $\mathrm{MBi}_{7}$ cluster ${ }^{22)}$ consisting of an alloying element $\mathrm{M}$ that is surrounded by $\mathrm{Bi}$ atoms. Therefore, the alloying effects were inevitably involved in this $M k$ parameter. The $M k$ level decreases with an increase in the electronegativity of pure metals but increases with an increase in the atomic

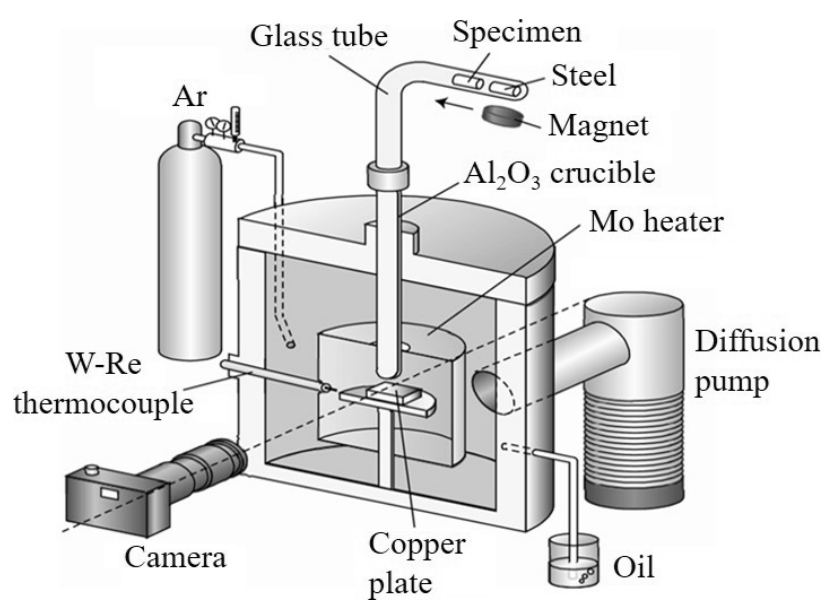

Fig. 1 Apparatus of contact angle tests.

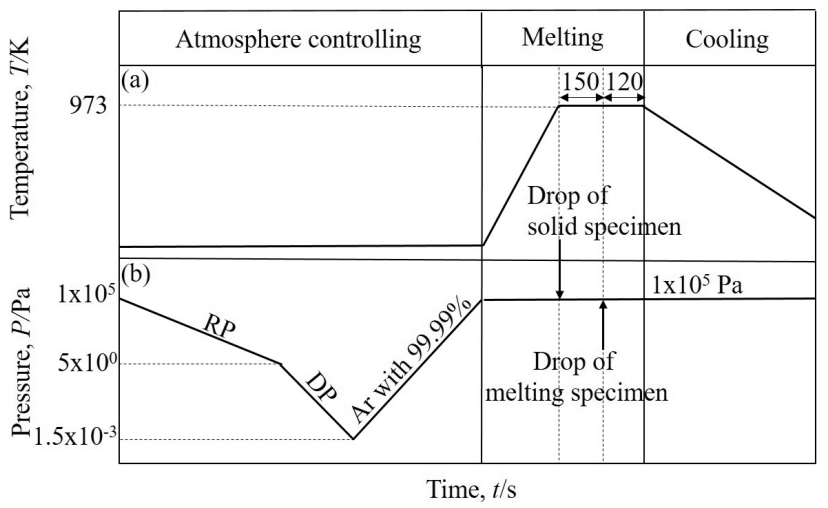

Fig. 2 Profiles of (a) temperature of $\mathrm{Cu}$ plate and (b) pressure in atmosphere of melting process. 
radius; this is in keeping with the relationship determined by using the $\mathrm{MAl}_{18}$ cluster as a model of face-centered cubic $\mathrm{Al}^{24)}$. It is well known ${ }^{25)}$ that the energy level determined through $\mathrm{X} \alpha$ calculations is representative of the electronegativity itself ${ }^{26-29)}$.

The value of the $M k$ parameter in the $\mathrm{MBi}_{7}$ cluster model was calculated using an octahedron of triclinic Bi. Using the $M k$ parameter, the $\Delta M k$ value for Bi alloys was defined using the compositional average, as given in eq. (1):

$$
\Delta M k=\Sigma X_{M}\left|M k_{\mathrm{M}}-M k_{\mathrm{Bi}}\right|
$$

where $X_{M}$ is the molar fraction of the alloying element $\mathrm{M}$, $M k_{\mathrm{M}}$ is the $M k$ value of the alloying element $\mathrm{M}$, and $M k_{\mathrm{Bi}}$ is the $M k$ value of the mother metal $\mathrm{Bi}$.

\section{Results and Discussion}

\subsection{Microstructures}

The microstructures of the as-cast Bi system alloys with the elements $\mathrm{Cu}$ or $\mathrm{Ag}$ are shown in Fig. 3. Pure $\mathrm{Bi}$ is a monophase of $\mathrm{Bi}$ and consists of equiaxial grains with a size of $45 \mu \mathrm{m}$. A primary $\mathrm{Cu}$ phase and a eutectic consisting of $\mathrm{Bi}$ and $\mathrm{Cu}$ are observed in the case of the $\mathrm{Bi}-0.15-1.0 \mathrm{Cu}$ alloys. The size of the primary $\mathrm{Cu}$ phase in the $\mathrm{Bi}-\mathrm{Cu}$ alloys increases with an increase in the $\mathrm{Cu}$ content. A primary $\mathrm{Ag}$ solid solution (hereafter called the Ag S.S.) and the eutectic of the $\mathrm{Bi}$ and $\mathrm{Ag}$ S.S. are observed in Bi-5.0Ag. In contrast, only the eutectic of the $\mathrm{Bi}$ and $\mathrm{Ag}$ S.S. is observed in $\mathrm{Bi}-2.5 \mathrm{Ag}$.

The microstructures of the Bi-2.0Ag- $0.5 \mathrm{Cu}$ and $\mathrm{Bi}-5.0 \mathrm{Ag}$ $0.5 \mathrm{Cu}$ alloys consisted of primary phases and a typical eutectic structure composed of $\mathrm{Bi}$, a $\mathrm{Ag} \mathrm{S}$.S., and a Cu S.S. in normal eutectic cells formed alternately, as shown in Figs. 3 (i) and (j). In the $\mathrm{Bi}-5.0 \mathrm{Ag}-0.5 \mathrm{Cu}$ alloy, which had a large $\mathrm{Ag}$ content, an irregular region consisting of a darker needle-like primary Ag S.S. and a light-contrast primary $\mathrm{Bi}$ phase surrounding the primary Ag S.S. were also observed; this was indicative of the crystallization of $\mathrm{Bi}$ in the depleted region of the Ag S.S. owing to the formation of the primary $\mathrm{Ag} \mathrm{S.S.} \mathrm{because} \mathrm{of} \mathrm{atomic} \mathrm{diffusion} \mathrm{under} \mathrm{the} \mathrm{nonequilib-}$ rium state (see Fig. $3(\mathrm{~h})$ ).

\subsection{Tensile properties at high temperatures \\ 3.2.1 Stress-strain behaviors}

Figure 4 shows the nominal stress-strain curves for 7 of the binary $\mathrm{Bi}$ system alloys as determined through tensile tests at $423 \mathrm{~K}$; that for pure $\mathrm{Bi}$ is shown as a reference. Typical softening can be seen in the stress-strain curves as compared to the curves obtained at $293 \mathrm{~K}^{22}$. The ultimate tensile strength and fracture strain of pure $\mathrm{Bi}$ were 4.2 $\mathrm{MPa}$ and $15.4 \%$, respectively. Thus, pure Bi exhibited the lowest ultimate tensile strength and fracture strain. For the Bi$0.15 / 0.25 / 0.5 / 0.75 / 1.0 \mathrm{Cu}$ alloys, the ultimate tensile strengths were $4.4,4.9,5.2,5.8$, and $5.4 \mathrm{MPa}$, respectively. Further, the fracture strains of these alloys were as least twice as large as that of pure $\mathrm{Bi}$, even though their ultimate tensile strength and flow stress values were only slightly greater than those of $\mathrm{Bi}$. In contrast, the ultimate tensile strength values of the $\mathrm{Bi}-2.5 / 5.0 \mathrm{Ag}$ alloys were 8.8 and 9.9 $\mathrm{MPa}$, respectively; these are 2.1 and 2.4 times greater,

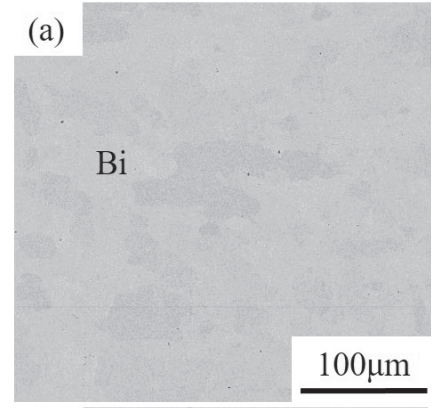

(b)
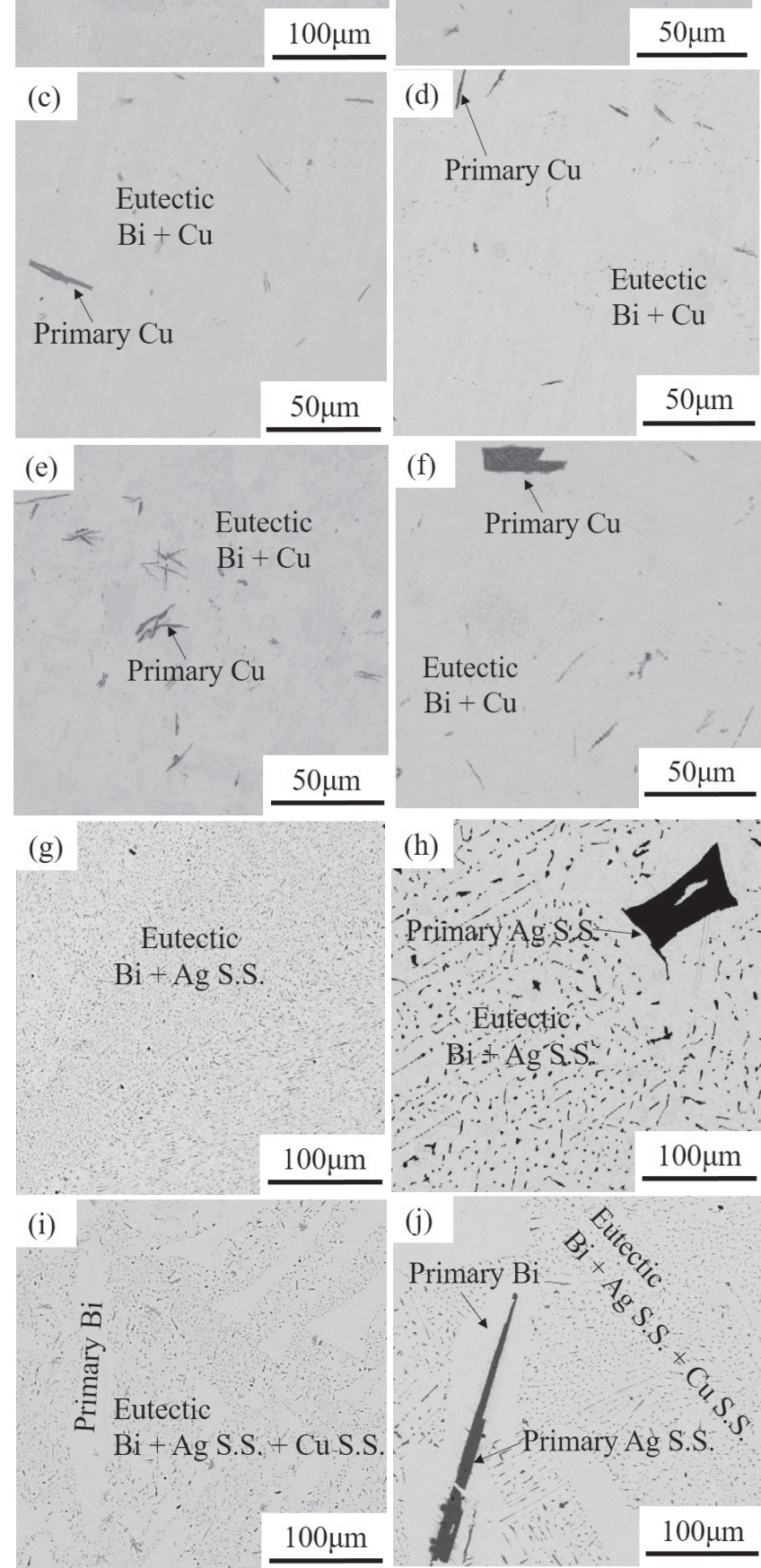

(f)
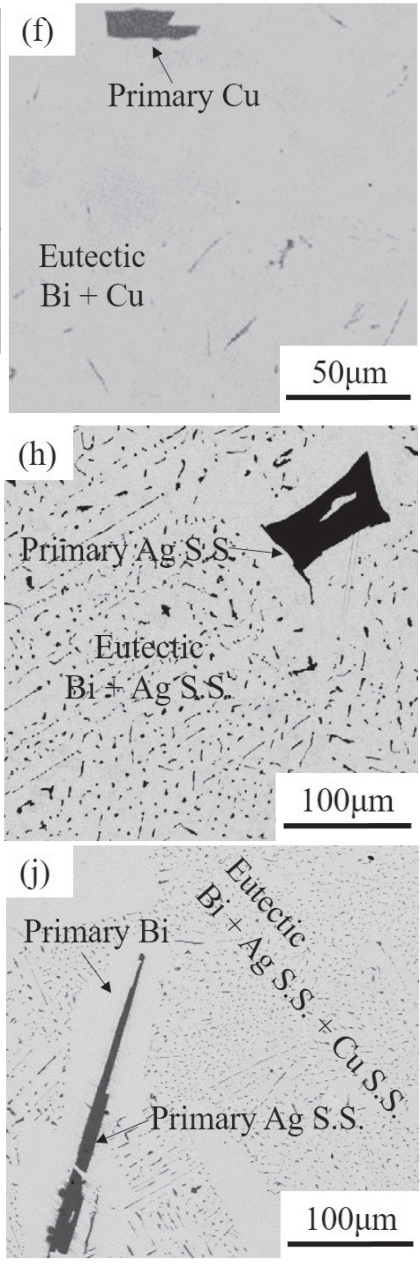

Fig. 3 Compositional images of (a) pure $\mathrm{Bi}$ and (b) $\mathrm{Bi}-0.15 \mathrm{Cu}$, (c) $\mathrm{Bi}$ $0.25 \mathrm{Cu}$, (d) Bi-0.5Cu, (e) Bi-0.75Cu, (f) Bi-1.0Cu, (g) Bi-2.5Ag, (h) Bi$5.0 \mathrm{Ag}$, (i) $\mathrm{Bi}-2.0 \mathrm{Ag}-0.5 \mathrm{Cu}$, and (j) $\mathrm{Bi}-5.0 \mathrm{Ag}-0.5 \mathrm{Cu}$ alloys

respectively, than that of pure $\mathrm{Bi}$. Moreover, the fracture strains of the two Bi-Ag alloys were similar to those of the $\mathrm{Bi}-\mathrm{Cu}$ system alloys. Thus, the tensile properties of the $\mathrm{Bi}$ alloys at $423 \mathrm{~K}$ improved with the addition of the alloying 
elements, namely, $\mathrm{Cu}$ and $\mathrm{Ag}$.

\subsubsection{Temperature dependence of tensile properties}

Figures 5 (a) and (b) shows the nominal stress-strain curves as determined at various temperatures of the ternary Bi-2.0Ag-0.5Cu and Bi-5.0Ag-0.5Cu alloys. The flow stress values of both alloys decreased with the increase in the test temperature, owing to the softening of the alloys. Therefore, the stress-strain curves were obtained at different test temperatures. In general, during plastic deformation, the alloys

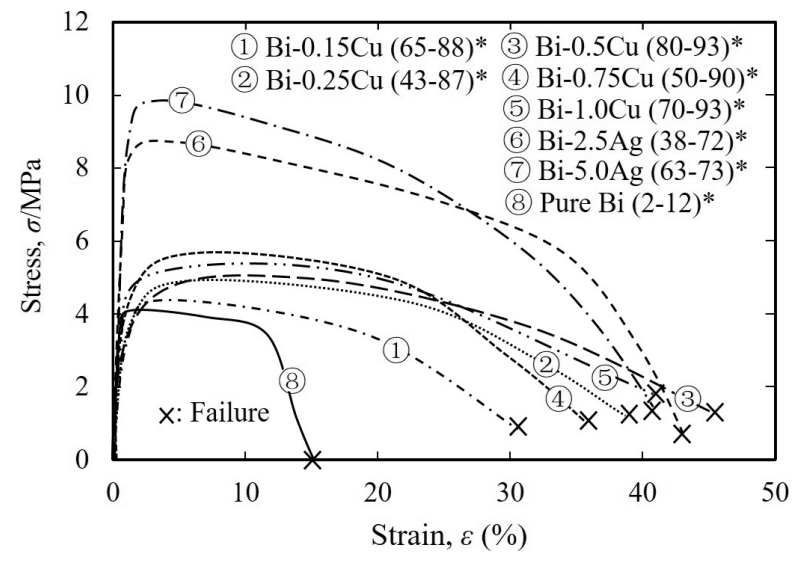

Fig. 4 Stress-strain curves at $423 \mathrm{~K}$ for $\mathrm{Bi}-0.15 \mathrm{Cu}^{22)}$, Bi- $0.25 \mathrm{Cu}, \mathrm{Bi}$ $0.5 \mathrm{Cu}^{22)}, \mathrm{Bi}-0.75 \mathrm{Cu}^{22)}, \mathrm{Bi}-1.0 \mathrm{Cu}, \mathrm{Bi}-2.5 \mathrm{Ag}$, and $\mathrm{Bi}-5.0 \mathrm{Ag}$ alloys and pure $\mathrm{Bi}^{22)}$. *Range of reduction in area $(\%)$ after failure.
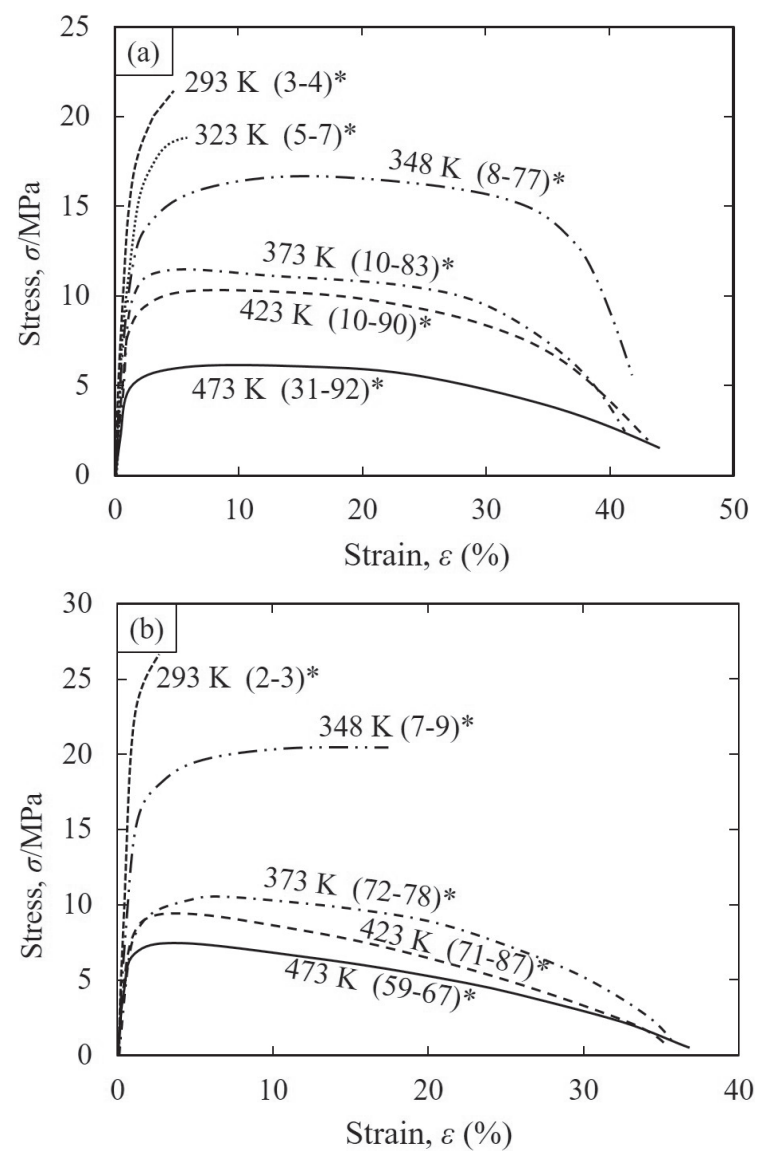

Fig. 5 Stress-strain curves of (a) Bi-2.0Ag-0.5Cu and (b) Bi-5.0Ag-0.5Cu alloys at 293, 323, 348, 373, 423, and $473 \mathrm{~K}$. *Range of reduction in area $(\%)$ after failure. experienced simultaneous work hardening and dynamic recovery, phenomena which have opposite effects on plastic deformation. Dislocation annihilation occurred more quickly than did dislocation generation, resulting in the weakening of the hardening phenomenon, as the test temperature was increased. This behavior has also been observed in the case of solder materials ${ }^{30)}$.

Both alloys showed a fracture strain of more than $17 \%$ even at $348 \mathrm{~K}$. The temperature dependence of the $0.2 \%$ proof stress and fracture strain of the ternary alloys is shown in Fig. 6. The $0.2 \%$ proof stress decreased with an increase in the temperature. In particular, between 323 and $348 \mathrm{~K}$ the temperature dependence of the $0.2 \%$ proof stress was stronger than that seen between 293 and $473 \mathrm{~K}$ in the case of Bi$2.0 \mathrm{Ag}-0.5 \mathrm{Cu}$. In contrast, the fracture strain increased sharply from 5.9 to $42.4 \%$ between 323 and $348 \mathrm{~K}$; this resulted in a transition from ductility to brittleness in this temperature range. Further, the ductile-to-brittle transition occurred at approximately $348 \mathrm{~K}$ in the case of $\mathrm{Bi}-5.0 \mathrm{Ag}-0.5 \mathrm{Cu}$. It was found that the decrease in the $0.2 \%$ proof stress was correlated to a significant increase in the fracture strain at temperatures between 323 and $373 \mathrm{~K}$. Therefore, these data confirmed the ductile-to-brittle transition temperature. The $\mathrm{Bi}-2.0 \mathrm{Ag}-0.5 \mathrm{Cu}$ and $\mathrm{Bi}-5.0 \mathrm{Ag}-0.5 \mathrm{Cu}$ alloys underwent ductile fractures at 348 and $373 \mathrm{~K}$, respectively, with dimples being present on the fracture surfaces. The fracture surfaces of the alloys at temperatures higher and lower than the ductile-to-brittle transition temperatures are shown in Fig. 7. The ductile and brittle fracture surfaces shown correspond to the deformation behaviors at temperatures higher and lower than the ductile-to-brittle transition temperatures.
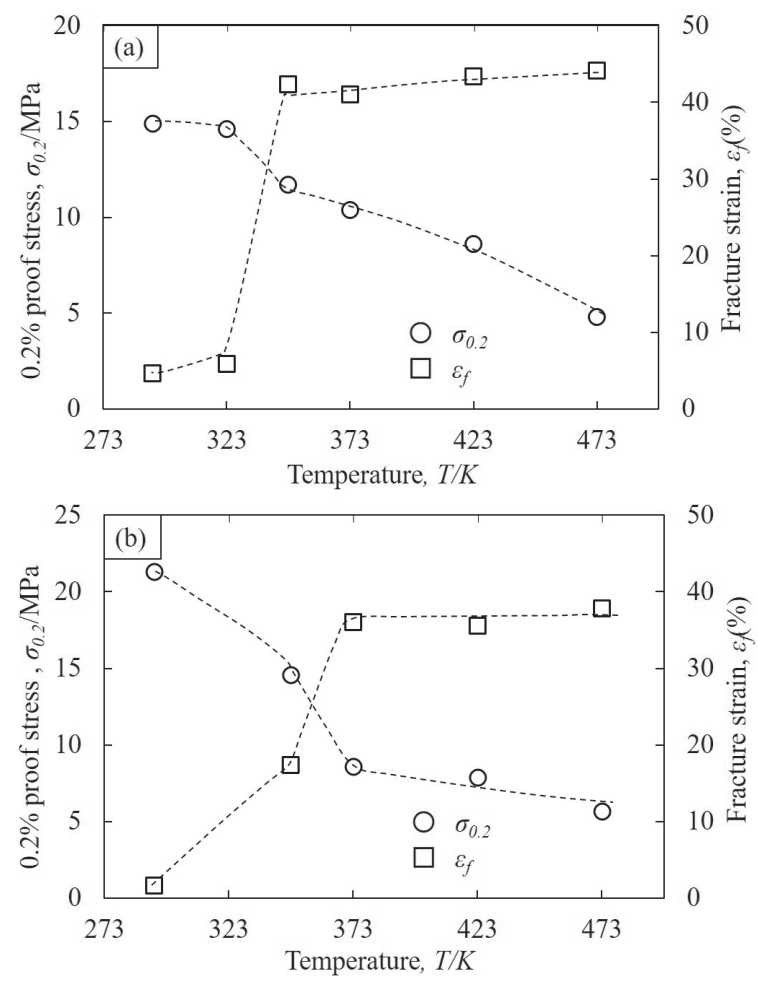

Fig. $6 \quad 0.2 \%$ proof stress and fracture strain at $293-473 \mathrm{~K}$ for (a) Bi2.0Ag-0.5 Cu and (b) Bi-5.0Ag-0.5Cu alloys. 

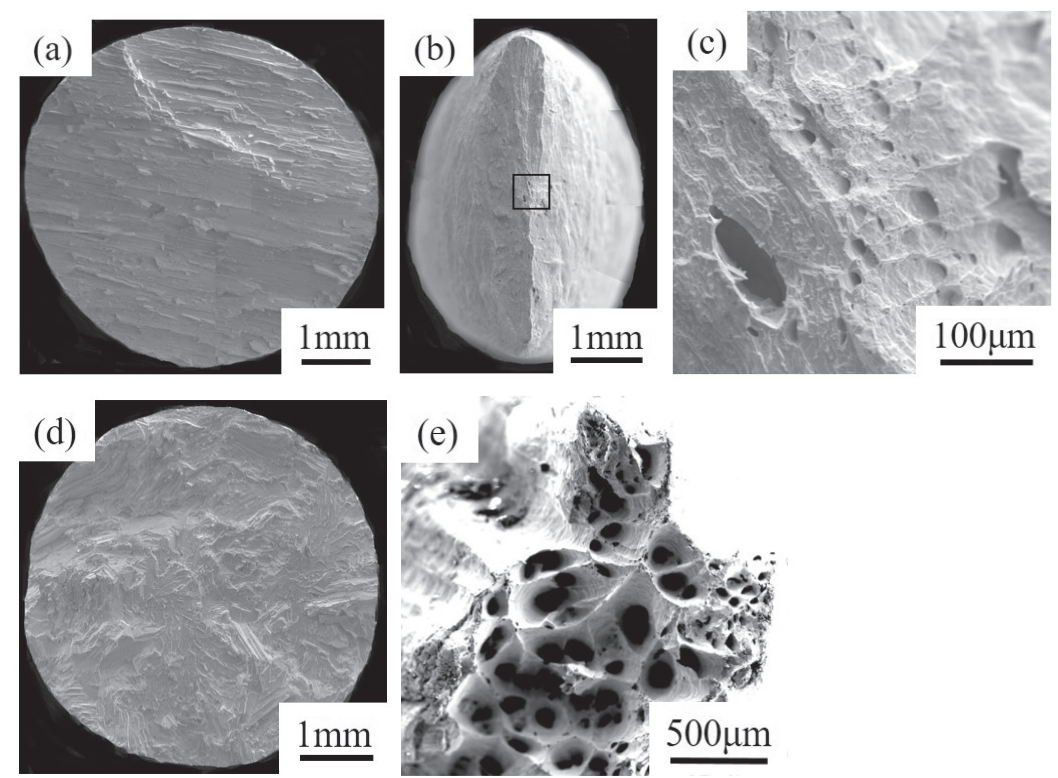

Fig. 7 SEM images of fracture surfaces of Bi-2.0Ag-0.5Cu specimens tensile tested at (a) $323 \mathrm{~K}$ and (b) $348 \mathrm{~K}$, and $\mathrm{Bi}-5.0 \mathrm{Ag}-0.5 \mathrm{Cu}$ specimens tensile tested at (d) $348 \mathrm{~K}$ and (e) $373 \mathrm{~K}$. (c) High-magnification image of area marked by black rectangle area in (b).
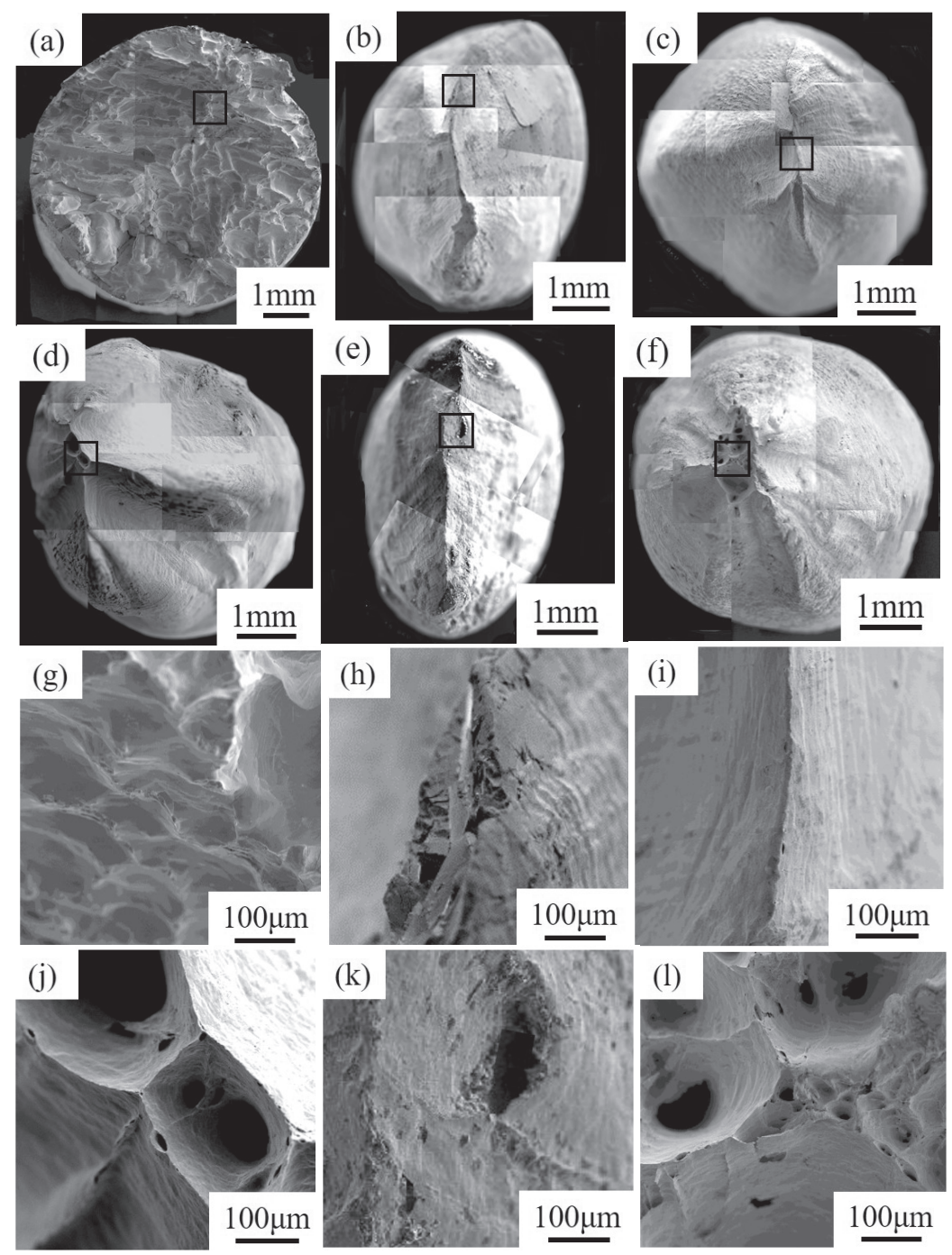

Fig. 8 SEM images of fracture surfaces at $423 \mathrm{~K}$ of (a) pure $\mathrm{Bi}^{22}$ and (b) $\mathrm{Bi}-0.15 \mathrm{Cu}$, (c) $\mathrm{Bi}-0.5 \mathrm{Cu}$, (d) $\mathrm{Bi}-5.0 \mathrm{Ag}$, (e) $\mathrm{Bi}-2.0 \mathrm{Ag}-0.5 \mathrm{Cu}$, and (f) $\mathrm{Bi}-5.0 \mathrm{Ag}-$ $0.5 \mathrm{Cu}$ alloys, and high-magnification images of fracture surfaces of $(\mathrm{g})$ pure $\mathrm{Bi}$ and (h) $\mathrm{Bi}-0.15 \mathrm{Cu}$, (i) $\mathrm{Bi}-0.5 \mathrm{Cu},(\mathrm{j}) \mathrm{Bi}-5.0 \mathrm{Ag},(\mathrm{k}) \mathrm{Bi}-2.0 \mathrm{Ag}-0.5 \mathrm{Cu}$, and (1) Bi-5.0Ag-0.5Cu alloys. The high-magnification images (g)-(l) correspond to areas enclosed in black rectangles in (a)-(f), respectively. 


\subsubsection{Fracture morphology}

The typical fracture surfaces of the $\mathrm{Bi}-0.15 / 0.5 \mathrm{Cu}$ and $\mathrm{Bi}-$ 5.0Ag alloys and pure $\mathrm{Bi}$ after the tensile tests at $423 \mathrm{~K}$ are shown in Fig. 8 (a)-(d) and (g)-(j). The pure Bi sample has a wavy fracture surface with undeveloped voids; however, the decrease in area (2-12\%) was the lowest in this case. In contrast, as shown in Figs. 8 (b), (c), (d), (h), (i), and (j), the fracture ends of the $\mathrm{Bi}-0.15 / 0.5 \mathrm{Cu}$ and $\mathrm{Bi}-5.0 \mathrm{Ag}$ alloys tested at $423 \mathrm{~K}$ had a dimple-like pattern consisting of several cavities, which were elongated along the stress axis close to failure. This resulted in a very large decrease in area, in keeping with the data shown Figs. 4 and 5. In addition, the fracture surface of $\mathrm{Bi}-0.15 \mathrm{Cu}$, which showed the lowest fracture strain, not only exhibited a ductile-fracture-like pattern but also a partially brittle-fracture-like pattern, even at $423 \mathrm{~K}$.

The Bi-2.0Ag-0.5Cu and $\mathrm{Bi}-5.0 \mathrm{Ag}-0.5 \mathrm{Cu}$ specimens, which showed fracture strains of 43.4 and $35.6 \%$, respectively, had their areas reduced by $10-90$ and $71-87 \%$, respectively. This was indicative of ductile failure and a heterogeneous and homogeneous increase in all three dimensions along the stress axis close to failure, respectively. Further, the fracture ends of the $\mathrm{Bi}-2.0 \mathrm{Ag}-0.5 \mathrm{Cu}$ and Bi-5.0Ag-0.5Cu specimens had a dimple-like pattern consisting of several cavities of different sizes.

\subsubsection{Relationship between tensile properties at $423 \mathrm{~K}$ and $\Delta M k$}

Figure 9 shows the relationship between the $0.2 \%$ proof stress, the ultimate tensile strength or fracture strain at $423 \mathrm{~K}$ (see Figs. 4 and 5), and $\triangle M k$. The $0.2 \%$ proof stress and ultimate tensile strength increased with an increase in $\Delta M k$ till approximately 0.18 and then remained almost constant; this was regardless of the type and amount of binary

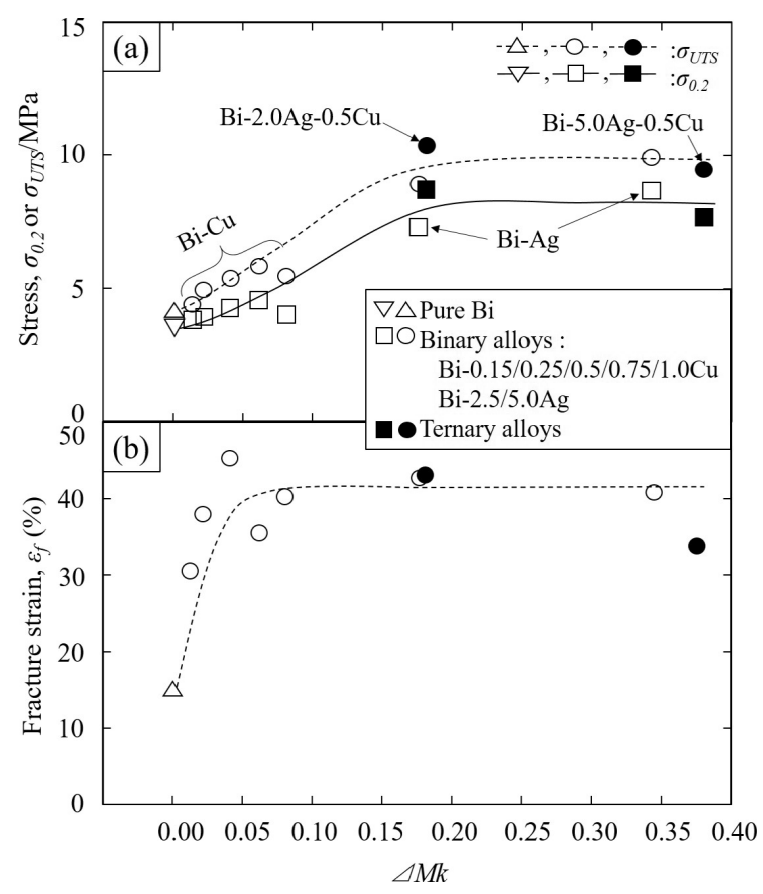

Fig. 9 Relationship between (a) $0.2 \%$ proof stress and ultimate tensile strength and (b) fracture strain at $423 \mathrm{~K}$ and $\Delta M k$ for experimental $\mathrm{Bi}$ system alloys. and ternary alloying elements used. This relationship at $423 \mathrm{~K}$ was similar to that seen at $293 \mathrm{~K}^{22}$. The $0.2 \%$ proof stress and ultimate tensile strength of pure Bi for a $\triangle M k$ of 0.00 could be also fitted using the relationship between the parameters and the $\triangle M k$ value for the experimental alloys. It is interesting to note that the measured stress levels of pure $\mathrm{Bi}$ agreed with those obtained by the extrapolation to $\triangle M k$.

On the other hand, the fracture strains of the binary and ternary Bi system alloys increased with an increase in $\triangle M k$ till approximately 0.08 and then remained almost constant. Thus, it can be assumed that the tensile properties of binary and ternary $\mathrm{Cu}$ - and Ag-containing Bi alloys at $293 \mathrm{~K}$ as determined based on $\Delta M k^{22)}$ can be used to evaluate their properties at $423 \mathrm{~K}$.

The number of slip systems also in the Bi alloys increased with an increase in the temperature. In addition, the effect of the precipitates on the retardation of the migration of dislocations was different for the different slip planes. Therefore, it may be considered that the relationship between the fracture strain and $\triangle M k$ changed with the increase in the test temperature. On the other hand, as shown in Fig. 3, the morphologies of the alloys changed with an increase in the amounts of the alloying elements. Thus, the phenomena arising from the retardation of dislocation migration, such as solid-solution hardening, precipitation hardening, and the Orowan effect, also changed. It may also be considered that the relationship between the alloy strength and $\Delta M k$ was not proportional to the change. Moreover, when the amounts of the alloying elements added were low levels, the relationship between the alloy strength and $\triangle M k$ was linear for both the binary and the ternary Bi system alloys.

\subsection{Melting points}

Figure 10 showed the DSC heating curves of the ternary $\mathrm{Bi}$ system alloys. The solidus temperatures of the Bi-2Ag$0.5 \mathrm{Cu}$ and $\mathrm{Bi}-5.0 \mathrm{Ag}-0.5 \mathrm{Cu}$ alloys were 536 and $538 \mathrm{~K}$, because of the eutectic structure shown in Fig. 3 (i) and (j), respectively. Based on these results, it can be surmised that the compositionally optimized $\mathrm{Bi}-\mathrm{Ag}-\mathrm{Cu}$ system alloys are suitable for use in practical applications requiring a melting point higher than $533 \mathrm{~K}^{1)}$.

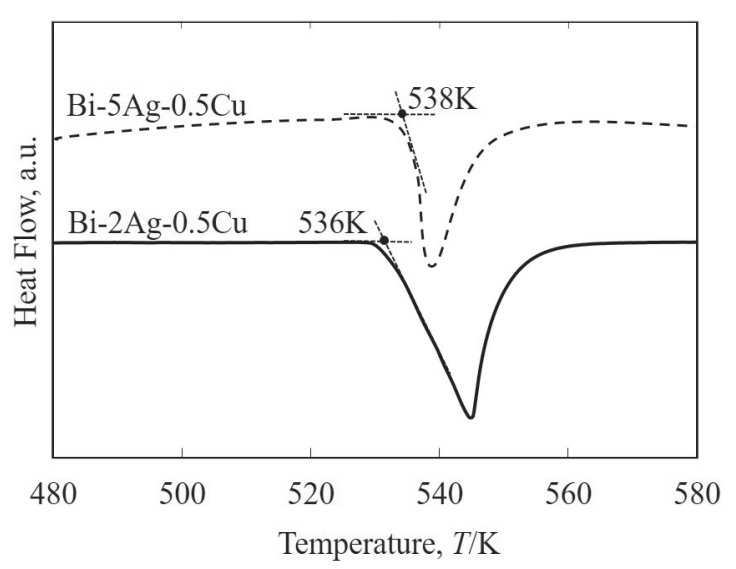

Fig. 10 DSC curves of Bi-2.0Ag-0.5 $\mathrm{Cu}^{23)}$ and $\mathrm{Bi}-5.0 \mathrm{Ag}-0.5 \mathrm{Cu}$ alloys. 

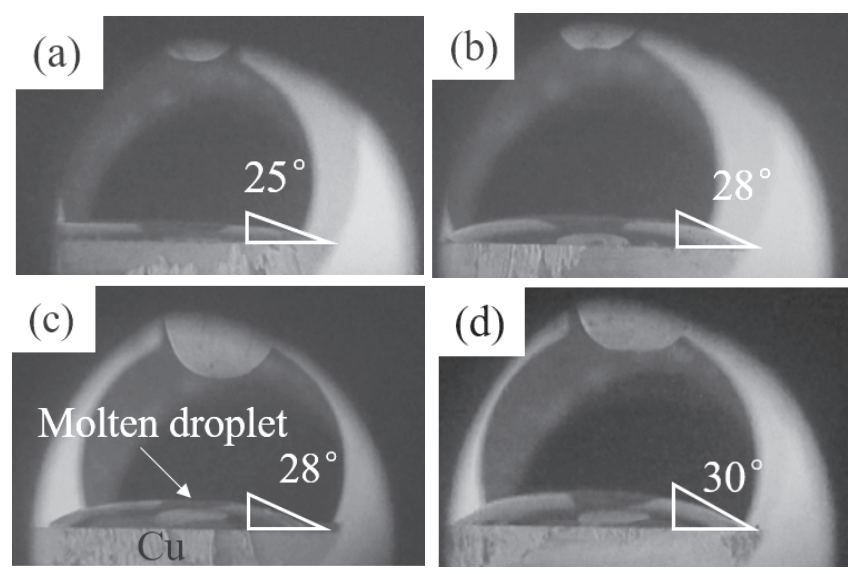

Fig. 11 Typical molten droplets of (a) pure $\mathrm{Bi}$, (b) $\mathrm{Bi}-0.75 \mathrm{Cu}$, (c) Bi$2.0 \mathrm{Ag}-0.5 \mathrm{Cu}$, and (d) $\mathrm{Bi}-5.0 \mathrm{Ag}-0.5 \mathrm{Cu}$ on $\mathrm{Cu}$ plate.

Table 2 Contact angles between droplets of experimental alloys and $\mathrm{Cu}$ plate as measured at $973 \mathrm{~K}$ in $\mathrm{Ar}$ atmosphere.

\begin{tabular}{cc}
\hline Alloy (mass\%) & Contact angle (degree) \\
\hline Pure Bi & 25 \\
\hline Bi- $0.15 \mathrm{Cu}$ & 26 \\
\hline $\mathrm{Bi}-0.25 \mathrm{Cu}$ & 27 \\
\hline $\mathrm{Bi}-0.5 \mathrm{Cu}$ & 29 \\
\hline $\mathrm{Bi}-0.75 \mathrm{Cu}$ & 28 \\
\hline $\mathrm{Bi}-1.0 \mathrm{Cu}$ & 29 \\
\hline $\mathrm{Bi}-2.5 \mathrm{Ag}$ & 25 \\
\hline $\mathrm{Bi}-5.0 \mathrm{Ag}$ & 24 \\
\hline $\mathrm{Bi}-2.0 \mathrm{Ag}-0.5 \mathrm{Cu}$ & 28 \\
\hline $\mathrm{Bi}-5.0 \mathrm{Ag}-0.5 \mathrm{Cu}$ & 30 \\
\hline
\end{tabular}

\subsection{Wettability}

Figure 11 shows typical droplets of pure $\mathrm{Bi}, \mathrm{Bi}-0.75 \mathrm{Cu}$, $\mathrm{Bi}-2.0 \mathrm{Ag}-0.5 \mathrm{Cu}$, and $\mathrm{Bi}-5.0 \mathrm{Ag}-0.5 \mathrm{Cu}$ on a $\mathrm{Cu}$ plate at $973 \mathrm{~K}$ in an Ar atmosphere. The contact angles for all the experimental alloys are listed in Table 2. It can be seen that the contact angles for all the specimens were $24-30^{\circ}$ (i.e., less than $90^{\circ}$ ), making the alloys suitable for use in practical applications.

\subsection{Thermal conductivity}

The thermal conductivity $(\lambda)$ values of the Bi-2.0Ag$0.5 \mathrm{Cu}$ and $\mathrm{Bi}-5.0 \mathrm{Ag}-0.5 \mathrm{Cu}$ alloys were measured at 293 $373 \mathrm{~K}$. Figure 12 shows the temperature and compositional dependence of $\lambda$. As can be seen from the figure, $\lambda$ decreased monotonously with an increase in the temperature; this was the case regardless of the alloy composition. Bi$5.0 \mathrm{Ag}-0.5 \mathrm{Cu}$ showed higher $\lambda$ values compared with $\mathrm{Bi}$ $2.0 \mathrm{Ag}-0.5 \mathrm{Cu}$, because of large amount of $\mathrm{Ag}$ in alloys. As the temperature is increased, the movement of the electrons becomes even more chaotic, resulting in a reduction in conductivity. Moreover, the $\lambda$ values of the alloys could be estimated using expressions that were functions of the temperature. For the same temperature, the $\lambda$ values of the designed alloys were lower than those of the conventional $\mathrm{Pb}-5 \mathrm{Sn}$ alloy. However, the $\lambda$ values of the ternary alloys need to be

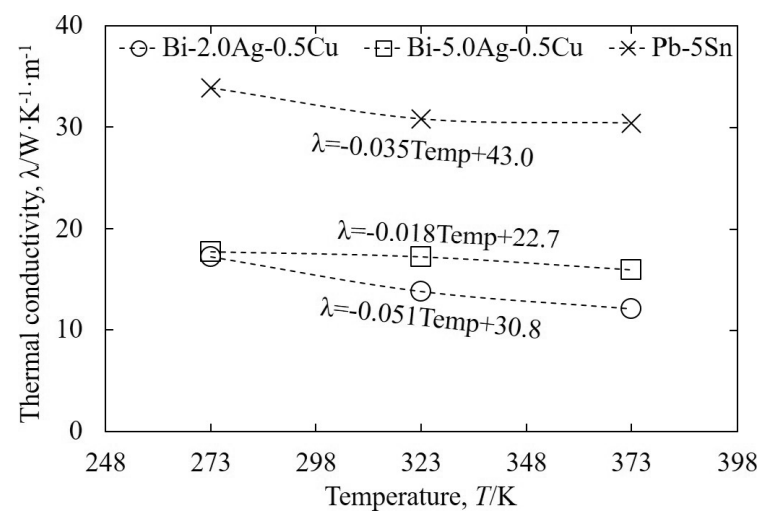

Fig. 12 Thermal conductivities of Bi-2.0Ag- $0.5 \mathrm{Cu}, \mathrm{Bi}-5.0 \mathrm{Ag}-0.5 \mathrm{Cu}$, and $\mathrm{Pb}-5 \mathrm{Sn}$ alloys for temperatures of $273-373 \mathrm{~K}$.

increased further in order for the alloys to be practically applicable.

\section{Conclusions}

(1) It was found that the $0.2 \%$ proof stress, ultimate tensile strength, and fracture strain of the designed binary Bi$\mathrm{Ag} /-\mathrm{Cu}$ alloys at $423 \mathrm{~K}$ were higher than those of pure $\mathrm{Bi}$. The $0.2 \%$ proof stress and ultimate tensile strength of the binary $\mathrm{Bi}$ system alloys increased with an increase in $\triangle M k$ till approximately 0.18 and then remained almost constant. In contrast, the fracture strain increased with an increase $\Delta M k$ till approximately 0.08 and then remained almost constant. The binary Bi system alloys exhibited excellent ductility, showing a fracture strain of more than $30 \%$ at $423 \mathrm{~K}$. The relationship between the strength at $423 \mathrm{~K}$ and $\triangle M k$ was similar to that observed during tests at $293 \mathrm{~K}$.

(2) The compositionally optimized alloys $\mathrm{Bi}-2.0 \mathrm{Ag}-0.5 \mathrm{Cu}$ and $\mathrm{Bi}-5.0 \mathrm{Ag}-0.5 \mathrm{Cu}$, which had $\triangle M k$ values of 0.180 and 0.379 , respectively, showed improved tensile properties at $423 \mathrm{~K}$ as compared to those of pure $\mathrm{Bi}$ and the binary $\mathrm{Bi}-\mathrm{Cu}$ alloys. Moreover, a transition from ductility to brittleness was observed at approximately 348$373 \mathrm{~K}$ in the case of both ternary alloys. It was found that the manner in which the mechanical properties of alloys can be predicted based on the $\triangle M k$ value would also be applicable in the case of the Bi system alloys investigated in this study, regardless of their composition and the tensile test temperature.

(3) The melting points of the alloys $\mathrm{Bi}-2.0 \mathrm{Ag}-0.5 \mathrm{Cu}$ and $\mathrm{Bi}-$ $5.0 \mathrm{Ag}-0.5 \mathrm{Cu}$ were determined to be 536 and $538 \mathrm{~K}$, respectively; these were within the desired range of melting temperatures for high-temperature solders. Further, the contact angles of molten droplets of 10 of the binary and ternary experimental alloys and a $\mathrm{Cu}$ plate at $973 \mathrm{~K}$ were determined to be $24-30^{\circ}$. This confirmed that the alloys exhibited suitable wettability with respect to $\mathrm{Cu}$. In addition, the ternary alloys $\mathrm{Bi}-2.0 \mathrm{Ag}-0.5 \mathrm{Cu}$ and $\mathrm{Bi}$ $5.0 \mathrm{Ag}-0.5 \mathrm{Cu}$ showed thermal conductivities of 12.1 and $15.9 \mathrm{~W} / \mathrm{m} / \mathrm{K}$, respectively, at $373 \mathrm{~K}$; these were lower than that $(30.4 \mathrm{~W} / \mathrm{m} / \mathrm{K})$ of $\mathrm{Pb}-5 \mathrm{Sn}$. 


\section{Acknowledgements}

We would like to express our thanks to Professors G. Sasaki and K. Sugio of Hiroshima University for their technical advice and experimental assistance. This study was financially supported by the Japan Foundry Engineering Society Fund. Parts of the study were also supported by the China Scholarship Council.

\section{REFERENCES}

1) S. Masayoshi, Y. Tomohiro, S. Kunio, N. Hiroshi and T. Tadashi: Trans. JWRI 41 (2012) 51-54.

2) H. Schoeller, S. Bansal, A. Knobloch, D. Shaddock and J. Cho: Mater. Sci. Eng. A 528 (2011) 1063-1070.

3) G. Zeng, S. McDonald and K. Nogita: Microelectron. Reliab. 52 (2012) 1306-1322.

4) S. Sakuyama, T. Akamatsu, K. Uenishi and T. Sato: Trans. JIEP 2 (2009) 98-103.

5) C. Leinenbach, F. Valenza, D. Giuranno, H. Elsener, S. Jin and R. Novakovic: Electron. Mater. 40 (2011) 1533-1541.

6) J. Pstrus, P. Fima and T. Gancarz: Mater. Eng. Perform. 21 (2012) 606-613.

7) T. Gancarz, J. Pstrus, P. Fima and S. Mosinska: Mater. Eng. Perform. 21 (2012) 599-605.

8) S. Kim, K.S. Kim, S.S. Kim and K. Suganuma: Electron. Mater. 38 (2009) 266-272.

9) Z. Xu, Y. Choi, T. Niimi, M. Yu, S. Motozuka, K. Matsugi and K. Suetsugu: Mater. Trans. 57 (2016) 553-557.

10) J. Song, H. Chuang and Z. Wu: Electron. Mater. 55 (2006) 1041-1049.

11) J. Song, H. Chuang and T. Wen: Metall. Mater. Trans., A 38 (2007) 1371-1375.
12) C. Wang, H. Chen and P. Li: Mater. Chem. Phys. 136 (2012) 325-333.

13) C. Leinenbach, F. Valenza, D. Giuranno, H.R. Elsener, S. Jin and R. Novakovic: Electron. Mater. 40 (2011) 1533.

14) T. Iseki and M. Takamori: J. Jpn. Inst. Electron. Packag. 15 (2012) 153.

15) J.C. Slater: Quantum theory of molecules and solids: The selfconsistent field for molecules and solids, Vol. 4, (McGrew-Hill, New York, 1974).

16) R. Ninomiya: Doctoral thesis, Toyohashi University of Technology (1996) pp. 124-130

17) M. Tsukada, H. Adachi and C. Satoko: Prog. Surf. Sci. 14 (1983) 113.

18) M. Morinaga and N. Yukawa: Computer Aided Innovation of New Materials, ed. by M. Doyama et al., (North-Holland, 1991) pp. 803-808.

19) M. Morinaga, N. Yukawa and H. Adachi: Tetsu-to-Hagané 72 (1986) $555-562$.

20) M. Morinaga, N. Yukawa, H. Adachi and H. Ezaki: Superalloys 1984, (The Metallurgical Society of AIME, Warrendale, PA, 1984) pp. 523-532.

21) K. Matsugi, S. Yamamura, Z.F. Xu, Y.B. Choi, K. Sugio, G. Sasaki and N. Oda: Mater. Trans. 56 (2015) 1675-1682.

22) M. Yu, Z. Xu, Y. Choi, T. Konishi, K. Matsugi, J. Yu, S. Motozuka and K. Suetsugu: Mater. Trans. 58 (2017) 140-147.

23) M. Yu, Z. Xu, Y. Choi, K. Matsugi, S. Motozuka, K. Suetsugu and J. Yu: 9th Pacific Rim International Conference on Advanced Materials and Processing (Kyoto, 2016) pp. 225-230.

24) M. Morinaga and S. Kamado: Model. Simul. Mater. Sci. Eng. 1 (1993) 151-164.

25) M. Moringa, S. Nasu, H. Adachi, J. Saito and N. Yukawa: J. J. Phys. 3 (1991) 6817.

26) R.S. Mullliken: J. Chem. Phys. 23 (1955) 1833

27) R.S. Mullliken: J. Chem. Phys. 23 (1955) 1841

28) R.S. Mullliken: J. Chem. Phys. 23 (1955) 2339

29) R.S. Mullliken: J. Chem. Phys. 23 (1955) 2343

30) E.A. Eid, A.N. Fouda and E.M. Duraia: Mater. Sci. Eng. A 657 (2016) 104-114. 